\title{
Pharmaceuticals and Intellectual Property: The US-Australia FTA
}

\section{John Quiggin}

I

n February 2004, the Australian Government announced the successful conclusion of negotiations for a Free Trade Agreement with the United States.

The Agreement, which was to come into force following ratification by the Australian Parliament and the US Congress, was the subject of vigorous and, at times, highly polemical debate in Australia. Of the main issues under discussion, two were familiar from previous debates over trade policy.

The first issue concerned estimates of the net economic benefits of the Agreement. While negotiations were underway, the Department of Foreign Affairs and Trade commissioned an analysis of costs and benefits of a possible agreement, in which it was estimated that a free trade agreement with the United States would produce net benefits with a present value of over \$A15 billion, arising mainly from improved market access for sugar and dairy products (Centre for International Economics, 2001). Estimated benefits to the US were slightly larger.

However, the actual terms of the Agreement were considerably less favourable than those anticipated by the Centre for International Economics (2001). In particular, there was no increase in access to the US market for Australian sugar, and only modest improvements for beef and dairy. Thus, the analysis of the Centre for International Economics (2001) implied that the likely benefits to Australia were small, and that the Agreement was unbalanced, in the sense that the benefits to the United States were considerably larger than those to Australia. Depending on the model of international trade negotiations that is adopted, it may or may not be beneficial, in the long run, to accept an agreement of this kind, in the absence of non-trade considerations of the kind discussed in this paper. The gain from accepting an unbalanced agreement may be offset by the signal to future negotiating partners of willingness to accept such a deal.

Nevertheless, a revised study by the Centre for International Economics (2004) estimated much larger net benefits for Australia, with a present value of \$A55 billion over 20 years, largely on the basis of new - and heroic assumptions about benefits from capital market integration. The Centre for International Economics (2004) assumed that relatively modest changes such as the removal of restrictions on US takeovers would yield economically significant reductions in the risk premium for equity.

This assumption is implausible. The proposed changes are tiny by comparison with the floating of the Australian dollar in 1983 and the associated

John Quiggin is an ARC Federation Fellow in Economics and Political Science at the University of Queensland. 
removal of exchange controls during the 1970s and 1980s, not to mention the associated liberalisation of domestic financial markets. Yet there is no convincing evidence that these changes had any net effect on the risk premium for equity. Australian regulators who have to use a risk premium in estimating the cost of capital have looked at this issue repeatedly, and none has yet been willing to base decisions on the assumption that the risk premium for equity has declined recently, relative to the 20th century as a whole.

The credibility of the analysis is further undermined by the fact that, having adopted speculative estimates of uncertain benefits from capital market liberalisation, the Centre for International Economics (2004) declined to make any numerical estimate of aspects of the agreement unfavourable to Australia, such as the extension of copyright terms.

Independent analysis, such as that of Dee (2004), generated much smaller estimates of the order of $\$ 100$ million each year for the goods trade component of the Agreement. Taking account of the uncertainties involved, it would be difficult to reject the hypothesis that, assessed in terms of standard neoclassical trade theory, the costs and benefits of the Agreement to Australia will be approximately equal, and that the net benefits will be approximately equal to zero.

The Agreement also gave rise to debate about the relative desirability of bilateral and multilateral agreements. Proponents of multilateral processes, such as Garnaut and Carmichael (2004), were strongly critical of the Agreement and argued that it would undermine both the World Trade Organisation (WTO) and prospects for improved trade relationships with Asia. On the other hand, supporters of the Agreement, such as the Australia United States Trade Agreement Business Group (AUSTA, 2003), argued that the failure of the Cancun round of WTO negotiations showed that multilateral processes could not be relied upon to produce progress towards freer trade or, alternatively, that bilateral and multilateral agreements were complements rather than substitutes. In addition, they pointed to the dynamic benefits of closer integration with the US economy (Oxley, 2002).

These issues were familiar from past debates. However, the Agreement also attracted critical attention from groups, including writers, health policy professionals and actors, whose concerns and interests had not previously figured prominently in trade policy. Actors, for example, were concerned with provisions regarding cultural protection such as requirements for minimum Australian content on television, which were the subject of an amendment to the implementing legislation. This issue is outside the scope of the present paper. Most of these concerns were related, in one form or another to the issue of intellectual property.

The debate over the Agreement has produced a book, How to Kill a Country: Australia's Devastating Trade Deal With the United States, primarily concerned with intellectual property and related issues (Weiss, Thurbon and Matthews, 2004). The polemical title of this work reflects the heated atmosphere of the debate and also, perhaps, the marketing requirements of a popular book on a complex issue likely to remain topical for only a few months. The authors provide 
a range of arguments to support the claim that, on balance, the Agreement will make Australians worse off, particularly in relation to issues such as copyright, quarantine and the Pharmaceutical Benefits Scheme (PBS). Nevertheless, even a highly unfavourable trade deal scarcely amounts to national devastation. Even if the Agreement doubled the cost of the PBS, for example, the resulting loss to Australia would be less than one per cent of GDP each year. Conversely, even the overoptimistic projections of the Centre for International Economics (2004) yield benefits of less than one per cent of GDP each year.

Weiss, Thurbon and Matthews justify their title by the claim that the Agreement 'threatens the core institutions of our country, and begins a process where they will be relentlessly substituted with the institutions of a foreign power'. This may sound hyperbolic, but except for the negative tone, it is not noticeably different from Oxley's (2002) description of the objective of the Agreement as securing 'comprehensive economic integration' with the United States. Clearly, comprehensive economic integration is not consistent with the maintenance of radically different economic institutions, and no-one is suggesting that the Agreement will lead the United States to adopt Australian institutions.

Weiss, Thurbon and Matthews pre-emptively defend themselves against a charge of anti-Americanism, claiming instead to be 'pro-Australian'. They argue that the United States Government has acted properly in advancing the interests of American citizens and corporations, and that the Australian Government has failed to do likewise.

In assessing the argument put forward by Weiss, Thurbon and Matthews, it is necessary to consider two questions: first, to what extent does the Agreement compel Australia to adopt policies modelled on those of the United States; and second, would a shift towards US policies make us better or worse off ?

In arguing that Australia will be worse off, Weiss, Thurbon and Matthews examine four areas of policy: pharmaceuticals, quarantine, copyright and government procurement. The implications of the Agreement in these policy areas forms the remainder of this paper. Of the four issues, pharmaceuticals was the most controversial in the debate over the Agreement and raised the most difficult economic issues; it will therefore be the primary focus of attention.

\section{Pharmaceuticals}

The provision of medicine has long been a concern of the Australian Government. At Federation, the only health responsibility allocated to the Commonwealth was quarantine. In 1946, however, the Constitution was amended by referendum to give the Commonwealth Parliament the power to provide 'medical and dental services (but not so as to authorize any form of civil conscription)'. This amendment paved the way for the National Health Act 1953 (Cwlth), which established the Pharmaceutical Benefits Scheme (PBS).

Although the PBS has been amended over time, the basic principles have remained unchanged. The scheme provides all Australians with access to a range of approved prescription drugs, subject to a small co-payment for concession 
holders (currently \$3.80) and a larger co-payment for the general public (currently \$23.10). Approved drugs are purchased from pharmaceutical companies at a price negotiated between the company and the Pharmaceutical Benefits Pricing Authority, a Commonwealth Government body. This price is the price to government, which is passed on to pharmacists, and does not include a wholesale margin.

Drugs are recommended for approval by a second body, the Pharmaceutical Benefits Advisory Committee, on the basis of a determination that the benefits of approval exceed the costs, taking account of the price demanded by the pharmaceuticals company concerned. The effect is to create a system of bilateral monopoly in relation to each product. The equilibrium price will lie between the marginal cost of supply (the lower bound of prices acceptable to the supplier) and the average benefit of the drug, as evaluated by the Committee. The difference between the price to pharmacists (including a pharmacy mark-up) and the price paid by patients is reimbursed by the government.

When negotiations towards the Agreement commenced in 2003, the Australian Government stated that the PBS was 'not on the table' (Campbell, 2003) and its supporters suggested that those who raised the issue were 'scaremongers' (Baume, 2003). This position was undermined when the US Congress passed a Medicare Bill in November 2003. Buried in the Bill's 1,100 pages was a clause requiring the Bush Administration to apprise Congress of 'progress in opening Australia's drug pricing system' (Becker, 2003). This was generally taken as code for the watering down or abolition of the PBS.

When the Agreement was finally announced in February 2004 it included extensive clauses relating to the operations of the PBS and provided enhanced protection for the US owners of drug patents. However, the Australian Government presented this outcome as a victory, arguing that the United States had demanded a right of appeal against adverse decisions from the Pharmaceutical Benefits Advisory Committee, but had received only the right to a nonbinding review of the Committee's decisions. The implementing legislation for the Agreement was passed by the Australian Parliament in August 2004. The legislation incorporated an amendment, proposed by the Labor Party that was designed to prevent a possible abuse of patent law through 'evergreening', a device by which patent-holders may extend the effective life of patents through trivial modifications to existing drugs. It was feared that evergreening, in combination with the increased protection for US patent-holders provided under the Agreement, might reduce the availability of cheaper generic drugs and thereby increase the cost of operating the PBS.

Labor's evergreening amendment was criticised vigorously, but was accepted when it attracted strong public support. The government's resistance to amendments concerned with the PBS reflected the importance placed by US negotiators on this issue, as did the reaction of US officials to the amended legislation. Although previously enthusiastic about the Agreement, representatives of the US Government were strongly critical of the amendment, and delayed certification of the Australian legislation implementing the 
Agreement — a step required for the Agreement to come into force. This resistance is indicative of the importance placed by the US Administration on the protection of intellectual property in pharmaceuticals and the perceived threat to intellectual property posed by interventions such as the PBS. US and other pharmaceutical companies have long been critical of the pricing practices of the PBS claiming that they do not provide an adequate return for the investment in research and development required to develop new drugs. Conversely, debate over the Agreement in Australia highlighted the importance placed by many Australians on the preservation of the PBS in its current form.

It is unclear, however, that the amended Agreement is a sustainable basis for maintenance of the PBS. Pearson (2004), in criticising the evergreening amendment, observes that it may be contrary to the Agreement in a number of respects. First, he says, the amendment may conflict with terms in the TradeRelated Aspects of Intellectual Property Rights (TRIPS) agreement that preclude discriminatory treatment of a specific sector such as pharmaceuticals. Second, there are general clauses in the Agreement that require 'standstill' in measures that would affect the relative positions of the parties. Third, US pharmaceutical companies might claim that they are being denied the 'reasonable benefits' available to them under the Agreement. Pearson argues that the effectiveness of the amendment could be annulled by an exchange of letters between the United States and Australia, binding the Australian Government not to act against the interests of US pharmaceutical companies.

It is important to observe that these points have nothing to do with the specific content of Labor's amendment. They apply to any legislation concerning the PBS that an Australian Government might seek to introduce in the future and, arguably, to any administrative decisions made by the government concerning the PBS. That is, on Pearson's analysis, the Agreement gives the United States an effective veto power over any changes made by an Australian Government to improve the functioning of the PBS, at least if these can be argued to harm the position of US pharmaceutical suppliers.

Weiss, Thurbon and Matthews (2004) develop these concerns with detailed reference to the review and transparency procedures set out in the Agreement. Their conclusion, which appears plausible, is that the PBS will not be sustainable in the long term in view of the pressure that can be applied by US pharmaceutical companies under the terms of the Agreement. The primary argument of these companies is that Australia is unfairly free-riding on pharmaceutical research undertaken in the United States and elsewhere by virtue of the monopsony power of the PBS. In the bargaining process leading up to the Agreement, the argument that Australia was not paying for research was used by US negotiators to seek more favourable treatment of US drug companies under the PBS.

In these circumstances it is important to consider whether the PBS makes an appropriate contribution to financing research and innovation in the pharmaceutical sector. Although the PBS has been an important element of Australian health policy since its establishment more than fifty years ago, it has rarely been critically examined or rigorously defended. Hence, before examining 
the Agreement it is necessary to consider the general question: how should we pay for pharmaceutical research?

\section{Paying for Pharmaceutical Research}

There is no dispute about the proposition that the producers of pharmaceuticals should receive payments sufficient to cover the marginal cost of production. Hence, the main issue is that of determining how society should pay for the medical research that is required to produce new pharmaceuticals. In an economy based primarily on market production, it is natural to start by looking at the freemarket solution. In the absence of government intervention, firms innovate in the hope of securing above-normal profits by offering a superior product. They discourage imitators using a variety of methods such as branding and trade secrecy.

Such methods will not protect a valuable innovation forever, but in some cases they deliver enough profits to finance a satisfactory rate of innovation. Examples include industries where innovation is focused on keeping up with rapidly changing consumer tastes, such as the fashion industry. There are good reasons to suppose that free markets will not deliver adequate levels of innovation in pharmaceuticals, however. The cumulative nature of scientific knowledge means that reliance on trade secrecy is neither feasible nor socially desirable. Branding has some effects, but the success of generic substitutes for branded products indicates that only modest price margins can be maintained through branding. Moreover, there is no guarantee that innovators will be more successful than imitators in building up brand identity.

To finance adequate levels of pharmaceuticals research, therefore, some form of government intervention may be necessary. There are three main options:

- patents;

- $\quad$ research grants; and

- $\quad$ research rewards.

Patents

Of the three main options, patents involve the most intrusive government intervention and the largest gross welfare costs. However, patents have advantages that, in some cases, more than offset these costs.

A patent is a temporary grant of monopoly rights, ${ }^{1}$ imposing civil and criminal penalties on those who produce and market goods that are inconsistent with the terms of the patent. Since a monopoly is analogous to a narrowly-based consumption tax, it has higher welfare costs than an equivalent sum raised from

1 Historically, the grant of patents on items such as salt and playing cards first emerged under the Tudor and Stuart monarchies in the late 16th century as a device for raising revenue and rewarding favourites. The award of patents as a reward for inventors came much later. 
general taxes. On the other hand, if the product market in question functions well in other respects (in particular, if consumers are well-informed and there are no cross-subsidies), the profit from the monopoly is a good measure of the social value of the innovation, eliminating the need for governments to make judgements on this issue. The only policy choice for governments is to find the optimal tradeoff between the duration of the patent and the cost to users of the inventions that are patented.

The problem in the case of pharmaceuticals is that the conditions for an efficient product market are not met. Consumers are largely reliant on the advice of doctors, who face a range of incentives that are unrelated to the social costs and benefits of alternative options. In general, medical ethics encourage doctors to seek the most effective treatment, without regard to costs. Institutional incentives modify this position, but often in ways that promote excessive intervention. For example, the risk of malpractice litigation may lead doctors to practise 'defensive medicine', prescribing tests and antibiotics even in cases where they are unlikely to be beneficial.

More generally, patients face cross-subsidies of various kinds, for example arising from public and private insurance. Patients are likely to bear the full cost of non-prescription medicines, which are relatively cheap, to make only partial payments for prescriptions filled by pharmacies and (at least in the case of public inpatients) to pay nothing for medicine supplied in hospitals. Hence, their patterns of demand indicate little about social costs and benefits.

\section{Research grants}

Research grants of various kinds are the basis of most fundamental research. This category includes both project-based grants of the kind funded by national medical research agencies, and the funding of universities and research institutes to undertake research without specific directions as to the content of that research. The most important benefit of grant-based research is that the products of research are freely available. Since the optimal price for a perfectly nonrival good is zero, a grant-based system achieves ex post efficiency in consumption. In recent times, some grant-funded researchers and institutions have sought a 'second bite at the cherry' through patents. This is an undesirable development, which, if it became the norm, would undermine the public-good character of grant-funded research. However, the amount actually raised in this way is smaller than is commonly imagined, and the public-good character of grant-funded research remains largely intact.

Since research grants are funded from general revenue, there is an associated deadweight loss, equal to the marginal social cost of tax revenue. Estimates of this deadweight cost vary widely, from near zero to 50 cents per dollar of additional revenue. Note that the marginal cost of general revenue, which is the cost associated with the most efficient available source of additional revenue, cannot be greater than the marginal cost of revenue from a narrowly-based tax or tax equivalent, such as the monopoly profit associated with a patent. 
The main problem with a grant-based model is the need for governments to make judgements about which projects or researchers to support. This is normally done through processes of peer review. Such processes appear to do a fairly good job of identifying the best performers in established lines of inquiry. However, they are less satisfactory in providing support for new and innovative lines of research, particularly if these are not undertaken within established institutions such as universities and research institutes.

\section{Research rewards}

The least familiar category of support for innovation is that of rewards for successful research. A famous historical instance is that of the Longitude prize, awarded by the British Government for the invention of a workable method of determining longitude at sea (Sobel, 1996). Explicit prizes of this kind are rare nowadays and are mostly privately funded. A recent example is the Kremer prize for human-powered flight, won by MacCready in 1977 with the Gossamer Condor (National Air and Space Museum, 2000).

For the purposes of the present argument, the Australian system of purchasing pharmaceuticals is, in essence, a reward-based system. An important difference is that the reward is not specified in advance and is contingent on the estimated social value of the new product. The operation of the rewards-based system presupposes that companies have patent rights, since otherwise Australia could simply produce the drug independently. Under the TRIPS agreement this option is available to poor countries, but not to developed countries like Australia.

Pharmaceutical companies with new and innovative products offer them to the Australian Government, which accepts them if the estimated social benefit of the drug exceeds the price demanded. For a bargain to be struck, the price must be somewhere between the company's marginal cost and the estimated net benefit to the Australian community. Where there is a wide gap, a standard bargaining problem arises, with the buyer seeking a price near the lower bound and the seller a price near the upper bound.

Because Australia is a small market, companies can cover most of their fixed costs in other markets such as the US, so that the marginal cost may be quite low. This strengthens Australia's bargaining position. On the other hand, the fact that fixed costs have already been covered means that companies can credibly threaten to withhold drugs from the Australian market if the payment is inadequate. In a game with repeated interactions, there is no reason to suppose that prices will inevitably be driven down to marginal costs.

It might be expected that a threat to withhold supply would be more credible in the case of an innovative drug offering substantial benefits, and the evidence appears to be consistent with this prediction. The Productivity Commission (2001) found that international price differences vary across classes of pharmaceuticals. Australian prices for new and innovative pharmaceuticals are much closer to those in other countries than prices for 'me-too' pharmaceuticals 
(patented drugs similar in function to those previously patented by competitors) and generic drugs, for which patent protection has expired.

On balance, it seems likely that the availability of monopoly profits for patented drugs in the US market reduces the equilibrium price in bargains between US pharmaceutical companies and the Australian PBS. But the magnitude of this effect is considerably smaller than the difference between Australian and US drug prices. US prices are inflated by factors such as expenditure on advertising (the United States is the only major jurisdiction that permits advertising of pharmaceuticals to consumers) and the incentives provided by the US system for the production of 'me-too' drugs.

It seems likely that, if the United States adopted a system similar to the PBS, there would be some increase in the equilibrium price for Australia. However, the improved incentives for the allocation of research effort would produce a significant increase in global welfare, relative to a system driven by monopoly profits on patents.

\section{Quarantine}

The provisions of the Agreement with respect to quarantine are similar in broad terms to those with respect to pharmaceuticals. That is, they provide the United States with consultation rights that have been represented by the Australian Government as implying no change to Australia's existing procedures, but which were nevertheless seen by the US negotiators as being of substantial significance. In principle, the quarantine provisions of the Agreement are symmetrical, giving similar consultation rights to Australia.

Quarantine policy involves trading off gains from trade in agricultural products against the risks to human health and domestic agricultural production from the importation of exotic pests and diseases. The political economy of quarantine is complicated by the fact that the domestic producers who benefit from a lower risk of disease also benefit from the protection against competition arising from restrictions on imports. Hence, domestic producers have an interest in lobbying for quarantine restrictions, regardless of the balance of costs and benefits to the nation as a whole. Conversely, advocates of freer trade have frequently looked at quarantine restrictions with suspicion. In principle, the problem could be addressed using the tools of risk analysis (Binder, 2002). In most cases, however, information on the probabilities associated with various adverse outcomes is unavailable, or too unreliable to form a basis for agreement on policy responses. As a result, less formal approaches have been adopted.

As Weiss, Thurbon and Matthews (2004) observe, Australia's existing quarantine procedures have been approved by the World Trade Organisation, under assessment processes that imply a presumption in favour of free trade. In the absence of a well-developed formal basis for risk analysis, the inclusion of the additional consultation mechanisms proposed in the Agreement implies that quarantine policy will give a higher weight to gains from trade than previously, 
and will give a correspondingly lower weight to concerns about disease and health.

Given the difficulty of assessing quarantine issues on a case-by-case basis, it seems reasonable to ask whether, in aggregate, quarantine and other phytosanitary restrictions appear to be in need of adjustment and, if so, in what direction. The most important recent failure of such restrictions has been associated with bovine spongiform encephelopathy (BSE or 'mad cow disease') and the resulting transmission to humans of Creutzfeld-Jakob disease (CJD), which is estimated to have caused more than 100 fatalities in the United Kingdom. The United Kingdom had earlier suffered from an outbreak of foot-and-mouth disease, triggering restrictions on travel that gravely affected the tourist industry. BarksRuggles (2001) reports that direct financial costs of the BSE epidemic are estimated to have exceeded 1.5 billion pounds, mostly associated with the slaughter of cattle at risk of infection, while the cost of the foot-and-mouth outbreak exceeded 5 billion pounds.

The emergence and spread of BSE has been associated with a range of innovations including the feeding of cattle on meal containing spinal and brain material from other cattle, and the development of more complex patterns of international trade in livestock. In addition, UK health authorities clearly erred on the side of protecting (short-term) producer interests in the early stages of the epidemic, by failing to act promptly and by providing reassurances that did not turn out to be soundly based. A similar pattern was observed in the United States, where resistance to testing may have facilitated the spread of BSE and the resulting loss of export markets.

Observation of the BSE case does not support the view that quarantine and phytosanitary restrictions are, in general, excessively strict. There may, however, be individual cases where the opposite is true. For example, Anderson and James (1998) argue that, even if imported diseases were to wipe out the Australian banana industry, the gains to consumers from cheaper imports would outweigh the losses to import-competing producers. On balance, however, it seems unlikely that using trade negotiations as a basis for reforming quarantine policy is likely to achieve an optimal trade-off between the benefits of freer trade and the costs of disease risks.

\section{Copyright}

Prior to the signing of the Agreement, Australia had one of the world's most liberal copyright regimes, with copyright extending a 'mere' fifty years beyond the author's death - compared to seventy years in the European Union and ninety-nine years in the United States. All of these terms are substantially longer than those prevailing when the first systematic copyright laws were introduced in Britain and the United States during the 18th century.

As part of the Agreement, Australia agreed to adopt a minimum copyright term of seventy years. And, as with other elements of the Agreement, there was no corresponding concession on the US side - not even a standstill provision. 
There is nothing to stop the United States from extending the term of copyright indefinitely. Indeed, there is every reason to suppose, based on the current balance of lobbying power within the United States, which heavily favours owners of intellectual property, that it will do so and that it will pressure Australia and others to follow.

It is hard to see any economic justification for a copyright term extending even fifty years beyond the author's death. For the vast majority of authors, the market value of copyright declines to zero within a few years of publication (Lessig, 2001). But even for the remaining minority, the incentive effect of a lowprobability financial payoff to be received by their heirs more than fifty years after their deaths must be trivially small in nearly every case. Of course, for the corporate owners of properties like Winnie the Pooh and Mickey Mouse, both of whom are at or near the relevant expiry dates, the rent associated with an extension of the copyright term is huge. It is unclear however, why trade mark protection could not be an adequate substitute for copyright, at least as far as merchandise is concerned.

The extension of copyright terms has a static monopoly cost, similar to that in the case of patents. A more fundamental concern, however, is the disincentive to the free dissemination of ideas. Large numbers of works are out of print, with copyright owners who are untraceable. Attempts to provide systematic access to large bodies of knowledge are regularly obstructed by copyright difficulties. It was for these reasons that a diverse group of economists, including Kenneth Arrow, James Buchanan, Ronald Coase and Milton Friedman submitted an amicus curiae (friends of the court) brief to the US Supreme Court (Arrow et al., 2002) in the case of Eldred $v$ Ashcroft in support of an (unsuccessful) challenge to the constitutionality of the Sonny Bono Copyright Term Extension Act, which added 20 years to existing and future copyrights. The issues have been discussed most extensively by Lessig (1999 and 2001), and in the Australian context by Boymal and Davidson (2003).

Like Lessig, Weiss, Thurbon and Matthews (2004) place the debate over copyright in the broader context of attempts, pursued most vigorously in the United States, to give the monopoly rights commonly referred to as 'intellectual property' all the civil and physical protection associated with property rights in real and financial assets, with no regard to the public good nature of information. The issues involved have been discussed above in relation to pharmaceuticals.

\section{Government Procurement}

The argument made by Weiss, Thurbon and Matthews (2004) on government procurement is, in essence, a restatement of the general observation regarding trade in goods and services, that the Agreement is biased in favour of the United States. For example, the Agreement allows requirements to 'set aside' a proportion of purchase contracts for domestic small businesses. On the US side, a small business is defined as having less than 1500 employees; in Australia it is less than 200. 
On this issue, Weiss, Thurbon and Matthews do not make a strong case that Australian rules regarding government procurement are more sensible, considered in terms of national policy, than those prevailing in the United States. On the contrary, they show some sympathy for US requirements to set aside a substantial portion of government contracts for small and medium enterprises, and for the generally entrenched 'Buy American' culture. Their position is more that, if the Americans are going to continue to tilt the procurement playing field in favour of local business, so should we.

This position does not seem appealing from an economic viewpoint. While it might be argued that standard government procurement rules unreasonably disadvantage small businesses, and that some level of set-aside is therefore justified, firms with 200 employees ought to be capable of competing in international markets. If anything, a lower rather than a higher threshold seems appropriate.

\section{Concluding Comments}

Considered purely as a trade agreement, the US-Australia Free Trade Agreement would have been beneficial to Australia if it had delivered a substantial bilateral movement towards free trade. However, because the Agreement allows the United States to retain its most damaging trade barriers, if considered purely as a trade agreement, the net benefits to Australia are near zero and quite possibly negative. It is the economic integration aspects of the Agreement, amounting to a decision by Australia to adopt the US agenda in favour of strong Intellectual Property rights that are of most concern. The strengthening of Intellectual Property rights is damaging even to the United States, which is a net exporter of Intellectual Property and is even more so in the case of Australia. Threats to the PBS are of particular concern in view of the central role of the Scheme in Australian health policy.

The Agreement may not, as Weiss, Thurbon and Matthews (2004) suggest, represent a road to national devastation. But it is lopsided in its trade aspects, damaging to the general multilateral trade process and dangerous in its expansion of the monopoly rights associated with intellectual property. Australia's negotiators should not have signed this Agreement and the Australian Parliament should not have ratified it.

\section{References}

Anderson, K. and S. James (1998), 'On the Need for More Economic Assessment of Quarantine/SPS Policies’, Centre for International Economic Studies Working Paper No. 98-02, University of Adelaide.

Arrow, K. et al. (2002), Amicus Curiae brief (of 17 economists) in the case of Eldred $v$ Ashcroft, Supreme Court of the United States, http://eldred.cc/legal/supremecourt.html. 
AUSTA (2003), 'A Stocktaking for the Bush Visit - Will Australia Luck in?', FTA Analyst: Issue 19, 21 October, AUSTA: The Australia United States Free Trade Agreement Business Group, http://www.austa.net/analyst/analyst19.html, viewed 12/1/05.

Barks-Ruggles, E. (2001), 'The Globalization of Disease', The Brookings Review 19(4):30-33.

Baume, M. (2003), ‘Anti-FTA Views Bunkum’, Australian Financial Review, 11 August.

Becker, E. (2003), 'Drug Industry Seeks to Sway Prices Overseas', New York Times, November 27.

Binder, M. (2002), 'The Role of Risk and Cost-Benefit Analysis in Determining Quarantine Measures', Productivity Commission, Staff Research Paper, AusInfo, Canberra http://www.pc.gov.au/research/staffres/quarantine/index.html.

Boymal, J. and S. Davidson, (2003), 'Extending Copyright Duration in Australia', Agenda, 10(2):129-144.

Campbell, I. (2003), Statement as Minister representing the Minister for Trade, Senate Hansard 2 December:1838.

Centre for International Economics (2001), 'Economic Impacts of an Australia-United States Free Trade Area', Report by the Centre for International Economics for the Department of Foreign Affairs and Trade, Canberra.

Centre for International Economics (2004), 'Economic Analysis of AUSFTA: Impact of the Bilateral Free Trade Agreement with the United States', Report by Centre for International Economics for the Department of Foreign Affairs and Trade, Canberra.

Dee, P. (2004), 'The Australia-US Free Trade Agreement: An Assessment', Paper prepared for the Senate Select Committee on the Free Trade Agreement between Australia and the United States of America, APSEG, Australian National University.

Garnaut, R. and B. Carmichael, (2004), 'Australia’s Approach to International Trade Negotiations: A Case Study, the USFTA', Submission to the Joint Standing Committee on Treaties, Inquiry into the Proposed Australia-United States Free Trade Agreement, Parliament of Australia (Submission No. 160).

Lessig, L. (1999), Code and Other Laws of Cyberspace, Basic Books, New York.

Lessig, L. (2001), The Future of Ideas: The Fate of the Commons in a Connected World, Random House, New York.

National Air and Space Museum (2000), 'MacCready “Gossamer Condor”., http://www.nasm.si.edu/research/aero/aircraft/maccread_condor.htm.

Oxley, A. (2002), 'Free Trade Agreements in the Era of Globalization - New Instruments to Advance New Interests - the Case of Australia', AUSTA: The Australia United States Free Trade Agreement Business Group, http://www.austa.net/reports/report1.htm.

Pearson, C. (2004), 'Subtle Bars to Free Trade’, The Australian, 21 August.

Productivity Commission (2001), International Pharmaceutical Price Differences, Research Report, AusInfo, Canberra. 
Sobel, D. (1996), Longitude: The True Story of a Lone Genius Who Solved the Greatest Scientific Problem of His Time, Penguin, London.

Weiss, L., E. Thurbon, and J. Matthews (2004), How to Kill a Country: Australia's Devastating Trade Deal With the United States, Allen \& Unwin, Crows Nest, NSW.

I thank Nancy Wallace and an anonymous referee for helpful comments and criticism. 